\title{
ON A BOUNDED SUBCLASS OF CERTAIN ANALYTIC FUNCTIONS SATISFYING A DIFFERENTIAL INEQUALITY
}

\author{
SukHwinder Singh, Sushma Gupta And SukHuit SingH
}

Abstract. In the present paper, using Jack's lemma, the authors investigate the differential inequality

$$
\left|(1-\alpha) \frac{I_{p}(n, \lambda) f(z)}{z^{p}}+\alpha \frac{I_{p}(n+1, \lambda) f(z)}{I_{p}(n, \lambda) f(z)}-1\right|<\mu, z \in E
$$

regarding multivalent functions defined by multiplier transfomation in the open unit disk $E=$ $\{z:|z|<1\}$. As consequences, sufficient conditions for univalence, starlikeness and strongly starlikeness of certain analytic functions are obtained.

Mathematics subject classification (2000): 30C45. mation.

Key words and phrases: Multivalent function, starlike function, convex function, multiplier transfor-

\section{REFERENCES}

[1] Aghalary, R., Ali, Rosihan M., Joshi, S. B. And RaVichandran, V., Inequalities for analytic functions defined by certain linear operators, International J. of Math. Sci., to appear.

[2] AL-AMIRI, H. S. AND READE, M. O., On a linear combination of some expressions in the theory of univalent functions, MONATSHEFTO FÜR MATHEMATIK, 80(1975), 257-264.

[3] Cho, N. E. AND SRIVAStava, H. M., Argument estimates of certain analytic functions defined by a class of multiplier transformations, MATH. COMPUT. MODELLING, 37(2003), 39-49.

[4] CHO, N. E. AND KIM, T. H., Multiplier transformations and strongly close-to-convex functions, Bull. Korean Math. Soc., 40(2003), 399-410.

[5] JACK, I. S., Functions starlike and convex of order $\alpha$, J. London Math. Soc., 3(1971), 469-474.

[6] JiAn, Li AND OwA, S., Properties of the Sălăgean operator, Georgian Math. J., 5, 4(1998), 361-366.

[7] Owa, S., SHEN, C. Y. AND OBRadović, M., Certain subclasses of analytic functions, Tamkang J. Math., 20(1989), 105-115.

[8] SăLĂGEAN, G. S., Subclasses of univalent functions, Lecture Notes in Math., 1013, 362-372, Springer-Verlag, Heideberg, 1983.

[9] Ponnusamy, S. AND SingH, V., Criteria for strongly starlike functions, Complex Variables: Theory and Appl., 34(1997), 267-291.

[10] Ponnusamy, S., Pólya-Schoenberg conjecture for Carathéodory functions, J. Londan Math. Soc., 51, 2(1995), 93-104.

[11] SINGH, S., GUPTA, S. AND SINGH, S., On a problem of univalence of functions satisfying a differential inequality, Mathematical Inequalities and Applications, vol. 10, No. 1(2007), 95-98.

[12] Singh, V., Singh, S. AND GuPTA, S., A problem in the theory of univalent functions, Integral Transforms and Special Functions, 16, 2(2005), 179-186.

[13] Uralegadd, B. A. And Somanatha, C., Certain classes of univalent functions, in Current Topics in Analytic Function Theory, H. M. Srivastava and S. Owa (ed.), World Scientific, Singapore, (1992), 371-374. 